\title{
Debt, economic growth, and interest rates: an empirical study of the Swiss case, presenting a new long-term dataset: 1894-2014
}

\author{
Guillaume Guex ${ }^{1}$ and Sébastien Guex ${ }^{2^{*}}$
}

\begin{abstract}
In this paper, relations between public debt, economic growth, and long-term interest rates in Switzerland from 1894 to 2014 are examined. For this purpose, an original long-term dataset on the general gross public debt in Switzerland, namely the aggregation of the Confederation gross debt, the cantons' gross debts, and the municipal gross debts, was reconstructed. Three different statistical approaches are performed to study relations between this aggregated debt, economic growth, and interest rates. The first consists of the study of correlations between GDP-weighted variables, the second is the study of the correlation between residuals of ARIMA time series models, and the last one studies vector autoregression (VAR) models, allowing us to test Granger causalities between variables. Every approach is performed on the whole time period but also on boom phases and recession phases independently. All the results suggest that the public debt during this period in Switzerland did not have a negative impact on economic growth and did not raise long-term interest rates.
\end{abstract}

Keywords: Public debt, Economic growth, Interest rates, Time series, Switzerland

\section{Background}

The issue of defining relations between public debt and economic growth is a highly controversial topic. From a theoretical viewpoint, the dominant or "conventional" idea, according to Elmendorf and Mankiw (1999, p. 1617), whose expression we will use henceforth, states that in the long term, a high public debt slows down economic growth. However, this point of view remains very much debated. From an empirical angle, researches tackling this question were already numerous before exploding subsequent to the worldwide financial crisis of 2008 and the "influential" (Panizza and Presbitero 2013, p. 180) work of Reinhart and Rogoff (2010). Nevertheless, on the one hand, these empirical researches suffer, for now, from several methodological flaws, weakening their conclusions (Panizza and Presbitero 2013). On the other hand, a

\footnotetext{
* Correspondence: sebastien.guex@unil.ch

${ }^{2}$ History Section, Faculty of Arts, University of Lausanne, 1015 Lausanne, Switzerland

Full list of author information is available at the end of the article
}

non-negligible part of them finds that this debt does not clearly or significantly influence economic growth. ${ }^{1}$

This article is aimed at empirically testing the conventional idea on the Swiss case between 1894 and 2014. In this respect, our research presents a first contribution. Several empirical studies that seem particularly interesting, because they have tested this idea for a high number of countries and over a very long-lasting period, take Switzerland into account, in particular the series of analyses based on the database established by S.A. Abbas. ${ }^{2}$ This database certainly has the advantage of supplying figures relative to the public debt in Switzerland that go back to 1899 . However, these figures concern only the debt contracted by the central state. Panizza and Presbitero (2013, p. 193 and p. 197) underline the methodological importance, for any empirical research, of the "definition of the debt itself," as it is possible to have an "enormous range" between "central government debt [and] general government debt." This is exactly the case in Switzerland. Since her creation in 1848, until today, Switzerland has remained one of the most federalist states 
in the world. This means that in Swiss public finances, the regional state structures (that is, the 26 cantons) and the local state structures (the thousands of municipalities) have more weight than the central state (the Confederation). The result is that not only does the central public debt usually form a minor part of the general public debt; it is also the case that the central government debt does not follow the same trend as the general government debt. Some figures show it clearly (two points) in 1910, 1925, 1950, 1975 , and 2000, the central gross public debt accounted for, respectively, 8.8, 40.5, 61.5, 27.3, and $49.8 \%$ of the general gross public debt. ${ }^{3}$ So, any empirical analysis based solely on central public debt must inevitably be strongly biased. Therefore, an important contribution of this research is to provide a dataset-the first of this kind-on the general gross public debt in Switzerland covering a long period: from 1894 to 2014 (see Additional file 1: Table SA.1). ${ }^{4}$

Secondly, to our knowledge, there exists only one published empirical study specifically concerning the Swiss case: the one done by Schwab (1996, pp. 134-136 and pp. 162-169). ${ }^{5}$ The author himself underlines that due to the "relatively short" period of time studied (1963-1992), "it is difficult to come to conclusive appraisals about the relations between public finances and economic growth in Switzerland" (Schwab 1996, p. 169). Thus, the second contribution of the present research is to remedy this problem by analyzing the Swiss case over a long period of time, namely 120 years.

A third asset of this paper is the use of various atheoretical methodologies in order to consolidate conclusions. Three analyses are performed: a study of correlations between GDP-weighted variables, a study of the correlation between residuals of ARIMA models, and reduced-form vector autoregression (VAR) modeling allowing us to test Granger causalities. For all analysis, time series are studied independently on economic growth (boom) phases, recession phases, and all phases together.

This study empirically tests two hypotheses supported by the conventional theoretical conception (Brunner, 1986; Schwab, 1996, pp. 103-104 and pp. 157-158; Elmendorf and Mankiw 1999, pp. 1615-1669; Blanchard 2008):

Table 1 Top: Pearson correlation coefficients between debt-to-GDP ratio and GDP growth rate for boom phases, recession phases and all data. Bottom: Pearson correlation coefficients between debt-to-GDP ratio and long-term interest rates for boom phases, recession phases and all data. Italics: significant results with 5\% level

\begin{tabular}{|c|c|c|c|c|c|c|}
\hline & $B_{t}=1$ & & $B_{t}=0$ & & $B_{t}=1$ or $B_{t}=0$ & \\
\hline$c$ & $\operatorname{cor}\left(D_{t}^{p}, G_{t+c}^{p}\right)$ & $p$ value & $\operatorname{cor}\left(D_{t}^{p}, G_{t+c}^{p}\right)$ & $p$ value & $\operatorname{cor}\left(D_{t}^{p}, G_{t+c}^{p}\right)$ & $p$ value \\
\hline-5 & 0.269 & 0.038 & 0.379 & 0.164 & -0.112 & 0.235 \\
\hline-4 & 0.284 & 0.022 & 0.373 & 0.115 & -0.129 & 0.166 \\
\hline-3 & 0.255 & 0.033 & 0.276 & 0.203 & -0.118 & 0.206 \\
\hline-2 & 0.227 & 0.051 & 0.158 & 0.431 & -0.105 & 0.258 \\
\hline-1 & 0.223 & 0.047 & 0.130 & 0.484 & -0.084 & 0.366 \\
\hline 0 & 0.255 & 0.019 & 0.038 & 0.829 & -0.006 & 0.949 \\
\hline 1 & 0.318 & 0.004 & 0.177 & 0.340 & 0.145 & 0.116 \\
\hline 2 & 0.100 & 0.392 & 0.016 & 0.936 & 0.131 & 0.159 \\
\hline 3 & 0.023 & 0.849 & 0.086 & 0.696 & 0.123 & 0.185 \\
\hline 4 & 0.034 & 0.791 & 0.133 & 0.588 & 0.116 & 0.217 \\
\hline 5 & 0.222 & 0.088 & 0.129 & 0.648 & 0.153 & 0.102 \\
\hline c & $\operatorname{cor}\left(D_{t}^{p}, O_{t+c}\right)$ & $p$ value & $\operatorname{cor}\left(D_{t}^{p}, O_{t+c}\right)$ & $p$ value & $\operatorname{cor}\left(D_{t}^{p}, O_{t+c}\right)$ & $p$ value \\
\hline-5 & -0.185 & 0.153 & -0.762 & 0.001 & 0.025 & 0.791 \\
\hline-4 & -0.145 & 0.246 & -0.785 & 0.000 & -0.003 & 0.977 \\
\hline-3 & -0.124 & 0.305 & -0.768 & 0.000 & -0.028 & 0.762 \\
\hline-2 & -0.101 & 0.386 & -0.730 & 0.000 & -0.050 & 0.588 \\
\hline-1 & -0.109 & 0.334 & -0.624 & 0.000 & -0.092 & 0.315 \\
\hline 0 & -0.128 & 0.240 & -0.621 & 0.000 & -0.146 & 0.110 \\
\hline 1 & -0.145 & 0.196 & -0.650 & 0.000 & -0.203 & 0.027 \\
\hline 2 & -0.143 & 0.217 & -0.606 & 0.001 & -0.241 & 0.008 \\
\hline 3 & -0.169 & 0.158 & -0.569 & 0.005 & -0.271 & 0.003 \\
\hline 4 & -0.223 & 0.072 & -0.499 & 0.030 & -0.303 & 0.001 \\
\hline 5 & -0.256 & 0.046 & -0.534 & 0.040 & -0.338 & 0.000 \\
\hline
\end{tabular}


Hypothesis 1 Public debt has a negative impact on economic growth.

Hypothesis 2 Public debt raises long-term interest rates.

The first hypothesis forms what we can call the general or basic hypothesis of the conventional theory. Following the large majority of other studies, this hypothesis will be tested by examining relations between the general gross public debt and the gross domestic product (GDP) in Switzerland.

The second hypothesis is more restrictive but plays a central role in the conventional theory. As a matter of fact, this theory often puts the increase of long-term interest rates at the very heart of mechanisms having a negative impact on economic growth. Hypothesis 2 will be tested by analyzing relations between the general gross public debt and the nominal yields on Confederation and/or Swiss Federal Railways bonds, which, in Switzerland, are generally considered to be the benchmarks for long-term interest rates.

This paper is divided as follows: the "Data" section presents data used for our research; the "Analyses and empirical results" section contains statistical analysis descriptions, results, and discussions; and, finally, conclusions are found in the "Conclusions" section.

\section{Data}

This section contains descriptions and sources for the five time series used in statistical analyses. Actual data figures, from 1894 to 2014, are found in Table SA.1 in Additional file 1.

\section{General gross public debt: $D_{t}$}

This time series consists of the aggregation of the gross debts of the Confederation, cantons, and municipalities. An important fact is that until 1910, it consists solely of the funded debt held by the public. The floating debts and the internal (or administrative) debts are not considered. However, the resulting bias is negligible because the amounts of these kinds of debts are, in fact, quite low before 1910 .

From 1911 to 1959, this aggregation includes the funded debts and the floating debts, as well as a large part of the internal debts, of the Confederation, the cantons, and the municipalities. From 1960 to 2014, it includes almost the entire internal debts of these three levels of the Swiss state. We made the choice to include, as far as possible, the internal debt, for the following two reasons:

(1)Internal debt, i.e., the part of the debt not held by the public but by different state or public institutions (e.g., public pension funds, public corporations such as the post, telegraph, and telephone), constitutes an important and growing part of the general gross public debt in Switzerland. When the Confederation debt is examined over time, its internal debt represents $9.9 \%$ of the total in $1920,18.6 \%$ in 1950 , and $29.7 \%$ in 2000 . Thus, we cannot consider the weight of the internal debt as negligible or weak.

(2)Not taking into account, this debt when empirically testing the conventional conception seems, from our point of view, to slightly diminish the robustness of the results.

This time series on general gross public debt is constructed from the following sources ${ }^{6}$ :

(a) From 1894 to 1910 :

- Confederation: Federal Statistical Office (1934, pp. 338-339);

- Canton and municipalities: Steiger (1915) and Steiger (1916). Data were collected for 1900 and 1910 and reconstructed with linear interpolation for other years. Note that results without interpolation are also discussed in the "Results without interpolated years" section.

\section{(b)From 1911 to 1989 :}

- Confederation: Swiss National Bank (1944, p. 199) before 1943; Federal Council, Compte d'Etat de la Confédération suisse, Bern, for every year between 1943 and 1989;

- Cantons: Steiger and Higy (1934, p. 424); Federal Statistical Office (1917, p. 355); Federal Tax Administration (1967, p. 35); Federal Tax Administration (1973, p. 29); Federal Administration of Finance (1978, p. 26); Kirchgässner (2004).

- Municipalities: Steiger and Higy (1934, p. 435); Federal Statistical Office (1932, p. 343, 1939, p. 347, 1947, p. 454, 1947, p. 404); Federal Tax Administration (1965, p. 55); Kirchgässner (2004, p. 22). This consists of estimations based on a sample from the major municipalities of Switzerland. Data from 1914 to 1918 were reconstructed with linear interpolation.

(c) From 1990 to 2014:

- Confederation, cantons, and municipalities: Swiss Federal Statistical Office, Table "Dettes des administrations publiques" (je-f-18.04.01.xls) https:// www.bfs.admin.ch/bfs/fr/home/statistiques/administration -finances-publiques.assetdetail.3462296.html (accessed October 28, 2016). The reconstruction of data with 
new standards leads to having a quantitative leap in 1990. The resulting bias is, however, reduced by the fact that a leap of comparable scale also occurs in the GPD time series in 1990, for similar reasons.

\section{Gross domestic product: $G_{t}$}

This time series comes from the following sources:

(a) From 1894 to 1948: Historical Statistics of Switzerland online, Table Q.16a, http://www.fsw.uzh.ch/hstat/ nls_rev/ls_files.php?chapter_var=./q (accessed August 20, 2016).

(b)From 1949 to 1989: Historical Statistics of Switzerland online, Table Q.16b, http://www.fsw.uzh.ch/hstat/ nls_rev/ls_files.php?chapter_var=./q (accessed August 20, 2016).

(c) From 1990 to 2014: State Secretariat for Economic Affairs (SECO), Table "GDP, production approach, not adjusted" https://www.seco.admin.ch/seco/en/ home/wirtschaftslage-wirtschaftspolitik/ Wirtschaftslage/bip-quartalsschaetzungen-/ daten.html (accessed August 23, 2016).

\section{Long-term interest rates: $O_{t}$}

In Switzerland, the annual average of yields on Confederation and/or Swiss Federal Railways bonds is traditionally considered the benchmark for long-term interest rates. ${ }^{7}$ From 1899 to 2014, the Swiss National Bank gives an almost complete time series about this annual average. From 1894 to 1898 , data were obtained by taking the mean between savings bank deposit rates and rates of the medium-term notes issued by banks.

This time series comes from the following sources:

(a) From 1894 to 1898: Swiss National Bank, Historical Time Series, Tables 4.3a_A and 4.6a_A, https:// www.snb.ch/en/iabout/stat/statrep/statpubdis/id/ statpub_histz_arch (accessed August 24, 2016).

(b)From 1899 to 2001: Ibid., Table 3.1_A; for the year 1915, Guex (1993, p. 453).

(c) From 2002 to 2014: Swiss National Bank, Monthly Statistical Bulletin, Table E4, https://www.snb.ch/en/ iabout/stat/statrep/statpubdis/id/statpub_statmon_ arch (accessed August 24, 2016).

\section{Consumer price index: $I_{t}$}

Data were deflated by using the consumer price index (set to be 100 in 2014).

This time series comes from the following sources:

(a) From 1894 to 1913: Historical Statistics of Switzerland online, Table H.17, http://www.fsw.uzh.ch/hstat/ nls_rev/ls_files.php?chapter_var=./h (accessed August 20, 2016).

(b)From 1914 to 2014: Swiss Federal Statistical Office, Statistical Encyclopedia, Table "cc-f-05.02.08.xls," https:/www.bfs.admin.ch/bfs/fr/home/statistiques/ catalogues-banques-donnees/tableaux.assetdetail. 4242093.html (accessed August 24, 2016).

\section{Dummy variable for the identification of boom/recession} phases: $B_{t}$

In our analyses, boom and recession phases are also treated independently in order to see if hypotheses are conditionally valid for different economic regimes. Years belonging to boom phases are noted with 1 and years belonging to recession phases with 0 .

This division is largely inspired from the one used in Müller and Woitek (2012, p. 114) and is based on the distinction between phases with positive GDP growth rate and phases with negative GDP growth rate. The boom phases are 1894-1913, 1922-1929, 1945-1973, 1980-1990, and 1997-2014. Recession phases are 1914-1921, 1930-1944, 1974-1979, and 1991-1996.

\section{Analyses and empirical results}

The empirical analysis of relations between macroeconomic data raises many issues. Ideally, when two variables are studied, all external factors have to be removed in order to focus only on direct links between these variables. One of the issues with debt and GDP is that both are subject to exponential growth and will be highly correlated if analyzed directly (Yule 1926). To address this issue, three methods are used here, ranging from the simple to the more complex.

1. In the first part, this trend is suppressed by using variables weighted by GDP. The latter expresses the annual output of the country; it can work as a weight, similar to the use of population in other studies. Note that even if this method is frequently employed, it is still highly questionable, as the GDP is simultaneously a weight and a studied variable. Analogous to many empirical researches on the same subject (see, e.g., Schwab 1996, p. 164; Elmendorf and Mankiw 1999, p. 1636; Panizza and Presbitero 2013, p. 6; Greiner and Fincke 2015), correlations between weighted variables are computed with a time lag going from -5 to +5 years.

2. In the second part, residuals of series ARIMA models are analyzed, as advocated in, e.g., Granger and Newbold 1974. Building ARIMA models for a time series permits the removal of the variability explained by the past values of the variable. The remaining unknown variability, i.e., the residuals of the model, represents the effects coming from 
external sources. Thus, by studying the correlation between residuals of different series, we examine if these external effects, or shocks, are linked together. Here again, the study of correlations between variables with a time lag going from -5 to +5 years is performed.

3. The last part is the most sophisticated one. Granger causality tests (Granger 1969) are performed, using reduced-form vector autoregressive (VAR) models, with the help of the methodology developed by Toda and Yamamoto (1995) to deal with integrated time series. Although this methodology is more complex and less intuitive, it is the most suitable one for analyzing such data.

\section{Deflated time series}

In Additional file 1: Table SA.1, debt and GDP are expressed in nominal value and do not take into account inflation, expressed by the variable $I_{t}$. Thus, analyses are performed on debt and GDP is expressed in constant francs of 2014, noted respectively as $D_{t}^{r}$ and $G_{t}^{r}$, and defined by:

$$
D_{t}^{r}=100 \times \frac{D_{t}}{I_{t}} \quad G_{t}^{r}=100 \times \frac{G_{t}}{I_{t}}
$$

These variables, along with $O_{t}$, are pictured in Additional file 1 with their linear regression curve.

\section{GDP-weighted series Method}

In this section, we are testing Hypothesis 1 by examining relations between debt-to-GDP ratio, $D_{t}^{p}$, and GDP growth rate, $G_{t}^{p}$, defined by:

$$
D_{t}^{p}=\frac{D_{t}^{r}}{G_{t}^{r}} \quad G_{t}^{p}=\frac{G_{t}^{r}}{G_{t-1}^{r}}
$$

These variables are pictured in Additional file 1. To test Hypothesis 2, debt-to-GDP ratio $D_{t}^{p}$ is compared with $O_{t}$.

After the weighting of variables, the Pearson correlation coefficient test is performed on $\left(D_{t}^{p}, G_{t+c}^{p}\right)$ and $\left(D_{t}^{p}, O_{t+c}\right)$, where, as described above, $c$ takes values between -5 and +5 . These correlation tests are performed independently on boom phases, recession phases, and with all phases taken together.

\section{Results}

The results are presented in Table 1.

\section{Discussion}

Debt-to-GDP ratio vs GDP growth rate (Table 1, top) In the study of relations between debt-to-GDP ratio and GDP growth rate, a positive significant correlation coefficient is found during boom phases with $c=\{-5,-4,-3,-1$, $0,1\}$. This might reflect the fact that during boom phases, both GDP and debt-to-GDP ratio are generally increasing. Anyhow, these results go against the temporality (except for $c=1$ ) and the sign of the effect advocated by the conventional theory. Yet, this result needs to be put into perspective, notably because the variable $G_{t}^{r}$ appears simultaneously in the $D_{t}^{p}$ denominator and the $G_{t}^{p}$ numerator, dangerously increasing the risk of finding spurious correlations.

Debt-to-GDP ratio and long-term interest rates (Table 1, Bottom) Regarding correlations between debtto-GDP ratio and long-term interest rates, very significant results are found for recession phases, although the sign of the correlation is the opposite of the one claimed by the conventional theory. The strength of the results is baffling, although finding an explanation to this phenomenon might need very complex schemes and is beyond the scope of this article. Note that these results should also be taken carefully: even if these time series are not constructed using a common variable, we can see in Additional file 1 that they are not stationary, which is a requirement for the results to be true asymptotically.

\section{Residuals of ARIMA models Method}

Another way to tackle the trend problem is to study correlations between residuals of series ARIMA models, as advocated in Granger and Newbold 1974. As a matter of fact, by building an ARIMA model, we try to forecast a series with its own past behavior, with residuals representing unexplained, external effects. By comparing correlations between residuals of different series, we study whether the shocks of these series are related.

ARIMA models are built from the Box-Jenkins methodology (Box et al. 2015). To begin with, we see that $D_{t}^{r}$ and $G_{t}^{r}$ seem to have an exponential behavior, as shown by their residuals. Knowing the multiplicative nature of these variables, this behavior can be expected, and it is quite standard to work with the logarithms of these quantities to avoid heteroskedasticity in residuals and to transform them into additive models. Let us define:

$$
D_{t}^{\ln }=\ln \left(D_{t}^{r}\right) \quad G_{t}^{\ln }=\ln \left(G_{t}^{r}\right)
$$

the natural logarithms of the general gross public debt and the gross domestic product (in ln-millions constant francs). These variables, shown in Additional file 1, seem 
to behave in a more linear way, as shown by their $R$-squared coefficients and residuals. Note that this logarithm transformation allows us to compare non-linear effects with linear models.

Following this step, the order of integration of the series must be obtained to ensure stationarity. In Additional file 1, autocorrelation and partial autocorrelation functions of the first difference series $\Delta D_{t}^{\mathrm{In}}, \Delta G_{t}^{\mathrm{In}}$, and $\Delta O_{t}$, defined by:

$$
\Delta D_{t}^{\ln }=D_{t}^{\ln }-D_{t-1}^{\ln } \quad \Delta G_{t}^{\ln }=G_{t}^{\ln }-G_{t-1}^{\ln } \quad \Delta O_{t}=O_{t}-O_{t-1}
$$

are displayed. These plots, along with the insignificant Kwiatkowski-Phillips-Schmidt-Shin (KPSS) test (Kwiatkowski et al. 1992) and the significant Augmented Dickey-Fuller (ADF) test (Dickey and Fuller 1979), indicate that all three series have an order of integration of one. Note that there is a doubt about $O_{t}$, as both KPSS and ADF tests are not significant for this variable, i.e., the time series seems not informative enough to be able to decide. However, its autocorrelation function, as shown in Additional file 1: Figure SE.5, displays a relatively slow decrease, favoring the use of its first differences.

Finally, model orders are determined by optimizing values of AICC and BIC. Note that for $\Delta O_{t}$, the AICC give a model ARMA $(0,3)$ and the BIC a model ARMA $(0,0)$. We opted here for the ARMA $(0,0)$ as it seems more parsimonious. In Additional file $1, \Delta D_{t}^{\ln }, \Delta G_{t}^{\ln }$, and $\Delta O_{t}$ are displayed. The respective models for $\Delta D_{t}^{\mathrm{ln}}, \Delta G_{t}^{\mathrm{ln}}$, and $\Delta O_{t}$ are ARMA $(1,0)$, ARMA $(0,0)$, and ARMA $(0,0)$. Thus, we only need to compute residuals for $\Delta D_{t}^{\mathrm{ln}}$, as $\Delta G_{t}^{\ln }$ and $\Delta O_{t}$ residuals are equivalent to their first difference series. The residuals series of $\Delta D_{t}^{\ln }$ is denoted by $\Delta D_{t}^{\text {res }}$.

Here again, Pearson correlation coefficient tests on $\left(\Delta D_{t}^{\text {res }}, \Delta G_{t+c}^{\mathrm{ln}}\right)$ and $\left(\Delta D_{t}^{\text {res }}, \Delta O_{t}\right)$ are performed independently on boom phases, recession phases, and all phases, where $c$ ranges from -5 to 5 .

\section{Results}

The results are presented in Table 2.

\section{Discussion}

First differences ln-debt vs residuals of first differences ln-GDP (Table 2, top) A strong significant result concerning Hypothesis 1 is between $\Delta D_{t}^{\text {res }}$ and $\Delta G_{t-1}^{\mathrm{ln}}$ for boom phases, with a strong negative correlation coefficient. This result implies that an increase (respectively a decrease) in the (ln-)GDP is followed next year by a decrease (respectively an increase) in the (ln-)debt residuals. One significant positive correlation coefficient is found for boom phases at $c=0$. The positive link for the same year indicates that shocks between these time series, due to external effects affecting them, often take a similar direction. Moreover, there is a link from the debt to the GDP for $c=4$ during recession phases. This link goes against the conventional theory, with the sign of the correlation indicating a positive effect of the debt on the GDP after a few years.

First differences ln-debt vs residuals of first differences interest rates (Table 2, Bottom) The results concerning Hypothesis 2 are different from the "Results" section. The only significant value, i.e., the correlation coefficient between $\Delta D_{t}^{\log }$ and $\Delta O_{t-2}$, which is equal to 0.252 , suggests that an increase (respectively a decrease) in the interest rates is followed by an increase (respectively a decrease) in the debt 2 years later. This reversed causality contradicts the results that are supported by Hypothesis 2 .

\section{Vector autoregression models and Granger causality Method}

This section holds the most appropriate analysis to test Hypotheses 1 and 2, namely by using Granger causality tests (Granger 1969) from reduced-form vector autoregression (VAR) models. Nevertheless, Park and Phillips (1989) and Sims et al. (1990), among others, show that the conventional asymptotic theory for hypothesis testing in this context is generally not suited when time series are integrated or co-integrated, which is the case here, as shown in Additional file 1. Hopefully, in their article, Toda and Yamamoto (1995) propose a methodology to tackle integration issues by fitting a model VAR $\left(p+d_{\max }\right)$ on nondifferentiated data, where $p$ is the lag length given by usual information criteria and $d_{\max }$ is the maximum order of integration of the series. Note that models are fitted with $p$ lags for coefficients estimations and orthogonal impulse responses, and the lag is increased only for testing Granger causalities. Even there, the $F$-test is performed only on the first $p$ coefficients of the VAR $\left(p+d_{\max }\right)$ model.

Unlike precedent methods performed in this article, the independent studies of boom phases and recession phases require more careful treatment. As a matter of fact, we can consider that coefficients of the VAR model will be different between boom phases and recession phases, as found in a Markov switching vector autoregression (MS-VAR) model, except that the switching years are known. In practice, different VAR models will be fit for boom phases, recession phases, and all phases, by hiding years not belonging to their respective set. However, VAR coefficients are estimated on lagged values that can lie outside the studied set. 
Table 2 Top: Pearson correlation coefficients between the residuals of first differences In-debt and residuals of first differences In-GDP for boom phases, recession phases and all data. Bottom: Pearson correlation coefficients between first differences In-debt and residuals of first differences interest rates for boom phases, recession phases and all data. Italics: significant results with 5\% level

\begin{tabular}{|c|c|c|c|c|c|c|}
\hline & $B_{t}=1$ & & $B_{t}=0$ & & $B_{t}=1$ or $B_{t}=0$ & \\
\hline c & $\operatorname{cor}\left(\Delta D_{t}^{\text {res }}, \Delta G_{t+c}^{\ln }\right)$ & $p$ value & $\operatorname{cor}\left(\Delta D_{t}^{\text {res }}, \Delta G_{t+c}^{\ln }\right)$ & $p$ value & $\operatorname{cor}\left(\Delta D_{t}^{\text {res }}, \Delta G_{t+c}^{\ln }\right)$ & $p$ value \\
\hline-5 & -0.015 & 0.896 & 0.056 & 0.771 & 0.056 & 0.549 \\
\hline-4 & 0.066 & 0.556 & -0.020 & 0.916 & 0.015 & 0.871 \\
\hline-3 & -0.026 & 0.813 & 0.016 & 0.932 & -0.012 & 0.897 \\
\hline-2 & 0.062 & 0.576 & 0.047 & 0.795 & 0.125 & 0.176 \\
\hline-1 & -0.447 & 0.000 & -0.126 & 0.479 & -0.461 & 0.000 \\
\hline 0 & 0.354 & 0.001 & -0.276 & 0.109 & 0.039 & 0.671 \\
\hline 1 & 0.110 & 0.318 & 0.128 & 0.469 & 0.031 & 0.735 \\
\hline 2 & 0.111 & 0.317 & -0.128 & 0.477 & 0.021 & 0.823 \\
\hline 3 & 0.060 & 0.591 & -0.118 & 0.521 & 0.050 & 0.596 \\
\hline 4 & -0.175 & 0.117 & 0.425 & 0.017 & -0.077 & 0.409 \\
\hline 5 & 0.204 & 0.070 & 0.088 & 0.646 & -0.097 & 0.305 \\
\hline$c$ & $\operatorname{cor}\left(\Delta D_{t}^{\mathrm{res}}, \Delta O_{t}\right)$ & $p$ value & $\operatorname{cor}\left(\Delta D_{t}^{\mathrm{res}}, \Delta O_{t}\right)$ & $p$ value & $\operatorname{cor}\left(\Delta D_{t}^{\text {res }}, \Delta O_{t}\right)$ & $p$ value \\
\hline-5 & -0.059 & 0.601 & 0.054 & 0.777 & 0.064 & 0.495 \\
\hline-4 & -0.029 & 0.799 & 0.111 & 0.552 & 0.027 & 0.776 \\
\hline-3 & -0.046 & 0.678 & -0.210 & 0.250 & -0.016 & 0.861 \\
\hline-2 & 0.201 & 0.068 & 0.090 & 0.617 & 0.252 & 0.006 \\
\hline-1 & 0.171 & 0.120 & 0.198 & 0.262 & 0.106 & 0.251 \\
\hline 0 & -0.180 & 0.100 & 0.004 & 0.981 & -0.121 & 0.189 \\
\hline 1 & -0.161 & 0.142 & 0.002 & 0.989 & -0.142 & 0.123 \\
\hline 2 & 0.097 & 0.381 & -0.183 & 0.308 & -0.011 & 0.904 \\
\hline 3 & 0.126 & 0.260 & -0.350 & 0.050 & -0.108 & 0.245 \\
\hline 4 & 0.113 & 0.315 & -0.014 & 0.940 & 0.100 & 0.287 \\
\hline 5 & -0.106 & 0.349 & 0.163 & 0.391 & 0.041 & 0.665 \\
\hline
\end{tabular}

As Granger causalities are studied for two pairs of variables, $\left(D_{t}^{\ln }, G_{t}^{\ln }\right)$ and $\left(D_{t}^{\ln }, O_{t}\right)$, and three different year subsets, there will be six different VAR models altogether. In the following section, we quickly summarize construction, assessment, and main results of every model. Supplementary statistics about these models can be found in Additional file 1 .

\section{Results}

VAR models for $\left(D_{t}^{\ln }, G_{t}^{\ln }\right)$

(a) Models' assessments

- Boom phases: The Johansen procedure (Johansen 1988) does not give any co-integration. All information criteria give a lag length of $p=2$. Residuals show no autocorrelation and no conditional heteroskedasticity, though they do not seem to follow a normal distribution, especially for $G_{t}^{\mathrm{ln}}$ (this problem is recurrent for several models; we will come back to this in the discussion).
- Recession phases: Here, the Johansen procedure does not give any co-integration. Criteria diverge on the lag length. For parsimony reasons, we opted for a lag length of $p=2$. With such a model, residuals have no autocorrelation and no conditional heteroskedasticity and follow a normal distribution.

- All phases: The Johansen procedure does not give any co-integration. Information criteria give a lag length of $p=2$. This model has no autocorrelation in residuals, though they are not normally distributed and show conditional heteroskedasticity.

(b) Models' coefficients

The models' coefficients are presented in Tables 3, 4, and 5.

(c) Orthogonal impulse response functions

The orthogonal impulse response functions are presented in Figs. 1, 2, and 3.

(d) Granger causalities 
Table 3 Coefficients' estimations of a VAR (2) model between the $D_{t}^{\ln }$ and $G_{t}^{\text {In }}$ for boom phases. Top: model for $D_{t}^{\mathrm{ln}}$. Bottom: model for $G_{t}^{\text {In }}$. Italics: significant results with $5 \%$ level

\begin{tabular}{cll}
\hline$D_{t}^{\ln }=$ & Coefficient & $p$ value \\
$D_{t-1}^{\ln }$ & 1.366 & 0.000 \\
$D_{t-2}^{\prime n}$ & -0.377 & 0.000 \\
$G_{t-1}^{\ln }$ & -0.586 & 0.000 \\
$G_{t-2}^{\ln }$ & 0.590 & 0.000 \\
Const & 0.072 & 0.027 \\
$G_{t}^{\ln }=$ & Coefficient & $p$ value \\
$D_{t-1}^{\ln }$ & 0.176 & 0.056 \\
$D_{t-2}^{\ln }$ & -0.142 & 0.128 \\
$G_{t-1}^{\ln }$ & 0.887 & 0.000 \\
$G_{t-2}^{\ln }$ & 0.077 & 0.413 \\
Const & 0.090 & 0.011 \\
\hline
\end{tabular}

- Boom phases:

$$
\begin{aligned}
& G_{t}^{\ln } \rightarrow D_{t}^{\ln }: F=23.932, p \text { value }=8.613 \mathrm{e}-10 \\
& D_{t}^{\ln } \rightarrow G_{t}^{\ln }: F=4.535, p \text { value }=0.012
\end{aligned}
$$

- Recession phases:

$$
\begin{aligned}
& G_{t}^{\ln } \rightarrow D_{t}^{\ln }: F=0.233, p \text { value }=0.793 \\
& D_{t}^{\ln } \rightarrow G_{t}^{\ln }: F=1.533, p \text { value }=0.224
\end{aligned}
$$

- All phases:

$$
\begin{aligned}
& G_{t}^{\ln } \rightarrow D_{t}^{\ln }: F=16.241, p \text { value }=2.569 \mathrm{e}-07 \\
& D_{t}^{\ln } \rightarrow G_{t}^{\ln }: F=1.031, p \text { value }=0.359
\end{aligned}
$$

VAR models for $\left(D_{t}^{\ln }, O_{t}\right)$

(a) Models' assessments

Table 4 Coefficients' estimations of a VAR (2) model between the $D_{t}^{\ln }$ and $G_{t}^{\mathrm{ln}}$ for recession phases. Top: model for $D_{t}^{\ln }$. Bottom: model for $G_{t}^{\text {In }}$. Italics: significant results with $5 \%$ level

\begin{tabular}{cll}
\hline$D_{t}^{\text {In }}=$ & Coefficient & $p$ value \\
$D_{t-1}^{n n}$ & 1.515 & 0.000 \\
$D_{t-2}^{n}$ & -0.539 & 0.003 \\
$G_{t-1}^{n n}$ & -0.001 & 0.997 \\
$G_{t-2}^{n}$ & 0.019 & 0.923 \\
Const & 0.051 & 0.505 \\
$G_{t}^{\mathrm{n} n}=$ & Coefficient & $p$ value \\
$D_{t-1}^{\mathrm{n}}$ & 0.099 & 0.542 \\
$D_{t-2}^{\mathrm{n}}$ & 0.520 & 0.759 \\
$G_{t-1}^{n}$ & 0.513 & 0.007 \\
$G_{t-2}^{n n}$ & 0.444 & 0.020 \\
Const & -0.083 & 0.254 \\
\hline
\end{tabular}

Table 5 Coefficients' estimations of a VAR (2) model between the $D_{t}^{\ln }$ and $G_{t}^{\text {In }}$ for all phases. Top: model for $D_{t}^{\ln }$. Bottom: model for $G_{t}^{\text {In }}$. Italics: significant results with $5 \%$ level

\begin{tabular}{lll}
\hline$D_{t}^{\ln }=$ & Coefficient & $p$ value \\
$D_{t-1}^{\mathrm{n} n}$ & 1.422 & 0.000 \\
$D_{t-2}^{\mathrm{n} n}$ & -0.441 & 0.000 \\
$G_{t-1}^{\mathrm{n}}$ & -0.432 & 0.000 \\
$G_{t-2}^{\mathrm{n}}$ & 0.445 & 0.000 \\
Const & 0.051 & 0.094 \\
$G_{t}^{\mathrm{ln}}=$ & Coefficient & $p$ value \\
$D_{t-1}^{\mathrm{n} n}$ & 0.038 & 0.664 \\
$D_{t-2}^{\mathrm{n} n}$ & -0.019 & 0.835 \\
$G_{t-1}^{\mathrm{n}}$ & 0.992 & 0.000 \\
$G_{t-2}^{\mathrm{n}}$ & -0.010 & 0.910 \\
Const & 0.031 & 0.379 \\
\hline
\end{tabular}

- Boom phases: The Johansen procedure does not give any co-integration. Most information criteria give a lag length of $p=3$. Residuals show no autocorrelation and no conditional heteroskedasticity, though they do not seem normally distributed, especially for $D_{t}^{\ln }$.

- Recession phases: The Johansen procedure gives a co-integration with $5 \%$ level. The majority of information criteria give a lag length of $p=2$. There is no autocorrelation in residuals and no conditional heteroskedasticity, though they do not seem normally distributed.

- All phases: The Johansen procedure gives no co-integration. The majority of information criteria give a lag length of $p=2$. With this model, there is no auto-correlation in residuals, though they possess conditional heteroskedasticity and are not normally distributed.

(b) Models' coefficients

The models' coefficients are presented in Tables 6, 7, and 8.

(c) Orthogonal impulse response functions

The orthogonal impulse response functions are presented in Figs. 4, 5, and 6.

(d) Granger causalities

- Boom phases:

$$
\begin{aligned}
& O_{t} \rightarrow D_{t}^{\ln }: F=4.037, p \text { value }=0.009 \\
& D_{t}^{\ln \rightarrow O_{t}}: F=0.119, p \text { value }=0.949
\end{aligned}
$$

- Recession phases:

$$
\begin{aligned}
& O_{t} \rightarrow D_{t}^{\ln }: F=0.768, p \text { value }=0.468 \\
& D_{t}^{\mathrm{ln}} \rightarrow O_{t}: F=1.101, p \text { value }=0.339
\end{aligned}
$$

- All phases:

$$
\begin{aligned}
& O_{t} \rightarrow D_{t}^{\ln }: F=3.928, p \text { value }=0.021 \\
& D_{t}^{\ln } \rightarrow O_{t}: F=1.194, p \text { value }=0.305
\end{aligned}
$$



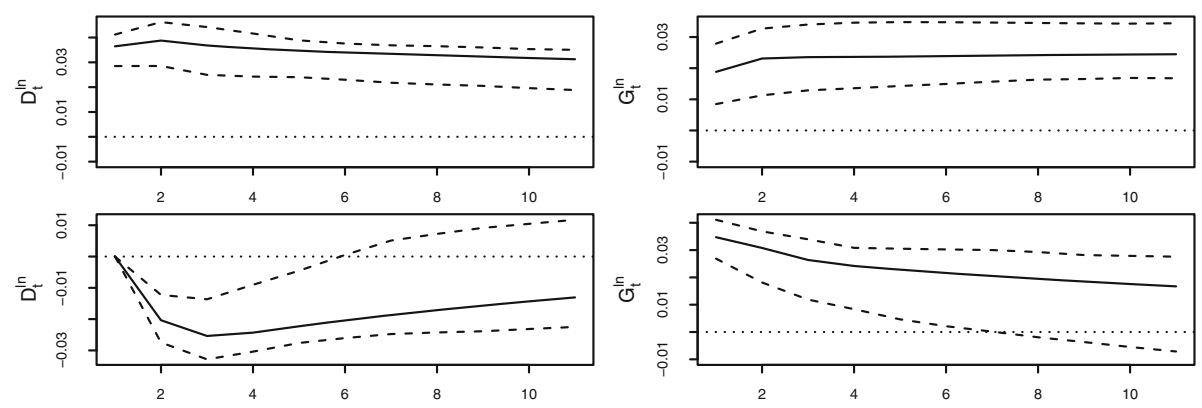

Fig. 1 Orthogonal impulse response functions with $95 \%$ bootstrap $C$ for boom phases. Top: from $D_{t}^{\ln }$ to $D_{t}^{\ln }$ and $G_{t}^{\ln }$. Bottom: from $G_{t}^{\ln }$ to $D_{t}^{\ln }$ and $G_{t}^{\ln }$

\section{Discussion}

Models' assessments First, let us briefly review the models' assessments. Almost every model (all except the model in the "VAR models for $\left(D_{t}^{\ln }, G_{t}^{\ln }\right)$ " section for recession phases) possesses residuals that are not normally distributed. Note that this is not surprising, as it is wellknown that when the number of data is large, most normality tests tend to become unnecessarily powerful, thus raising the amount of type I errors. Moreover, as long as the residuals are "reasonably" normal, this is barely an issue in order to build models for exploratory purposes. Models concerning all phases also have some heteroskedasticity in residuals. The latter certainly reflects the fact that these models are built without distinguishing boom phases and recession phases, and variances between these phases are highly different. This observation highlights the importance of the additional, independent studies of boom phases and recession phases. Apart from these remarks, the models seem reasonable: Granger causality and impulse response functions analyses can be performed.

Ln-Debt vs ln-GDP (the "VAR models for $\left(D_{t}^{\ln }, G_{t}^{\ln }\right)$ " section) These analyses reveal results close to the ones obtained in the "Residuals of ARIMA models" section. For the relation $G_{t}^{\ln } \rightarrow D_{t}^{\ln }$, there is a negative Granger causality during boom phases and all phases (as indicated by the significant Granger $F$-values, part d, and by negative impulse response functions, Figs. 1 and 3, bottom-left graphs). We also see a weak positive causality for $D_{t}^{\ln } \rightarrow G_{t}^{\ln }$ during boom phases (significant $F$-value, part $d$, and positive impulse response functions, Fig. 1, top-right graph), but we see that $G_{t}^{\mathrm{ln}}$ is largely explained by its previous values (Tables 3,4 , and 5 , right part). Again, these results contradict Hypothesis 1: they show that raising the (ln-)GDP decreases future (ln-)debt and, with weaker evidence, that (ln-)debt has a beneficial impact on future (ln-)GDP.

Ln-Debt vs interest rates (the "VAR models for $\left(\mathrm{D}_{t}^{\ln }, \mathrm{O}_{\mathrm{t}}\right)$ " section) About the relation between (ln-)debt and interest rates, the only causality found is a positive relation from $O_{t}$ to $D_{t}^{\ln }$ during boom phases and all phases (as indicated by the significant Granger $F$-values, part d, and by positive impulse response functions: Figs. 4 and 6, bottom-left graphs), thus showing a reversed temporality compared to the one suggested by Hypothesis 2. This result leads us to think that an increase in interest rates leads to a larger (ln-)debt in the following years, maybe because of the inability to reduce the debt amount due to the payment of interest.

Remarks An important remark should be made about the Granger causality. The reduced form of the VAR
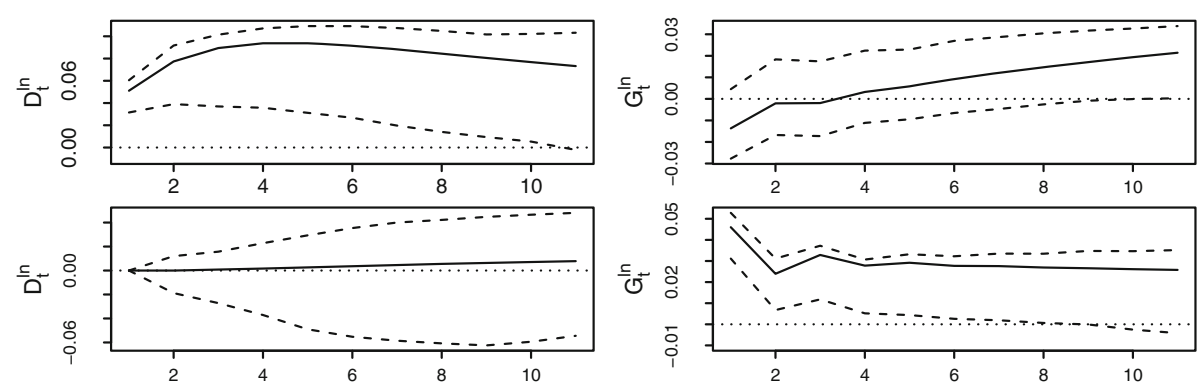

Fig. 2 Orthogonal impulse response functions with 95\% bootstrap $C$ for recession phases. Top: from $D_{t}^{\ln }$ to $D_{t}^{\ln }$ and $G_{t}^{\ln }$. Bottom: from $G_{t}^{\mathrm{ln}}$ to $D_{t}^{\mathrm{ln}}$ and $G_{t}^{\mathrm{ln}}$ 


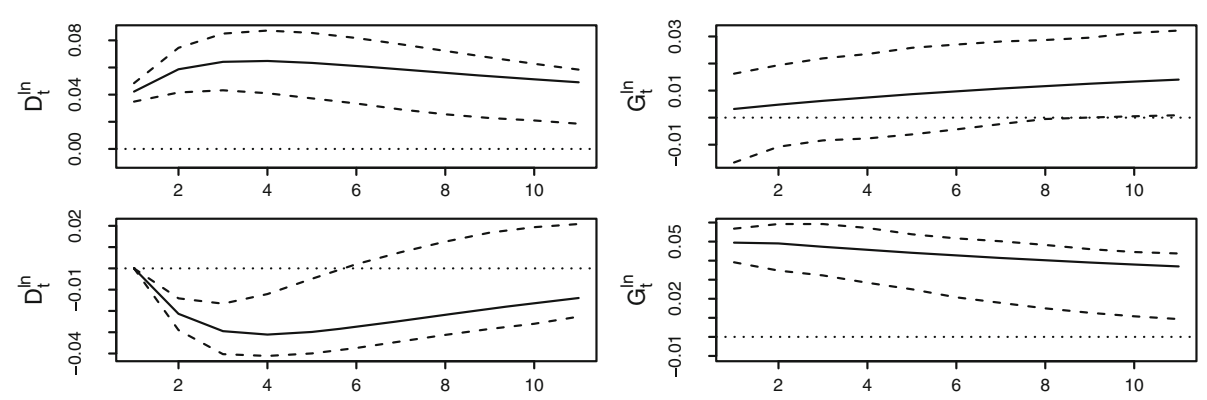

Fig. 3 Orthogonal impulse response functions with $95 \%$ bootstrap $C l$ for all phases. Top: from $D_{t}^{\ln }$ to $D_{t}^{\ln }$ and $G_{t}^{\ln }$. Bottom: from $G_{t}^{\ln }$ to $D_{t}^{\ln }$ and $G_{t}^{\ln }$

models used to construct Granger causality tests leads to a weaker form of negative results. Indeed, even though a positive Granger causality test is a strong argument in favor of a relationship between variables, a negative result is not strict evidence of the exogeneity of one variable regarding another (Cooley and Leroy 1985). A way to solve this issue would be to build structural VAR models (SVAR); however, this would imply a set of restrictions between variables and our approach would lose its atheoretical aspect. Nevertheless, these negative results tend to reinforce the results found in previous sections, and the accumulation of weak evidences works against the viability of Hypothesis 1 and Hypothesis 2.

\section{Results without interpolated years}

In this article, we have chosen to present and to work with the complete time series from 1884 to 2014.

Table 6 Coefficients' estimations of a VAR (3) model between the $D_{t}^{\mathrm{ln}}$ and $O_{t}$ for boom phases. Top: model for $D_{t}^{\mathrm{ln}}$. Bottom: model for $O_{t}$. Italics: significant results with $5 \%$ level

\begin{tabular}{cll}
\hline$D_{t}^{\ln }=$ & Coefficient & $p$ value \\
$D_{t-1}^{\ln }$ & 1.215 & 0.000 \\
$D_{t-2}^{\ln }$ & -0.142 & 0.422 \\
$D_{t-3}^{\ln }$ & -0.076 & 0.496 \\
$O_{t-1}$ & -0.005 & 0.702 \\
$O_{t-2}$ & 0.043 & 0.014 \\
$O_{t-3}$ & -0.033 & 0.009 \\
Const & 0.015 & 0.726 \\
$O_{t}=$ & Coefficient & $p$ value \\
$D_{t-1}^{\ln }$ & -0.427 & 0.701 \\
$D_{t-2}^{\ln }$ & 0.426 & 0.803 \\
$D_{t-3}^{\ln }$ & -0.024 & 0.982 \\
$O_{t-1}$ & 1.284 & 0.000 \\
$O_{t-2}$ & -0.631 & 0.000 \\
$O_{t-3}$ & 0.367 & 0.002 \\
Const & 0.103 & 0.863 \\
\hline
\end{tabular}

However, the debts for cantons and municipalities are missing between 1885-1899 and 1901-1909 and have been reconstructed by linear interpolation. Therefore, it is justified to wonder what would be the results without those interpolated years, as these years could lead to biased relationships between variables. This is the reason why we re-applied our three methods with data from 1910 to 2014, thus omitting interpolated years. Results of this study can be found in Additional file 1, and we will shortly discuss the differences from previous results.

First of all, let us note that all interpolated years belong to a boom phase. Thus, in the first and third experiments, results are modified only for boom phases and all phases, leaving recession phases results unchanged. However, ARIMA models are built considering all years, so even recession phases results are slightly altered.

By comparing results with and without interpolated years, we can see that interpretations remain mostly unchanged. In the study of GDP-weighted series, the correlation between $\left(D_{t}^{p}, G_{t-2}^{p}\right)$ becomes significant during boom

Table 7 Coefficients' estimations of a VAR (2) model between the $D_{t}^{\mathrm{ln}}$ and $O_{t}$ for recession phases. Top: model for $D_{t}^{\mathrm{ln}}$. Bottom: model for $\mathrm{O}_{t}$. Italics: significant results with $5 \%$ level

\begin{tabular}{cll}
\hline$D_{t}^{\ln }=$ & Coefficient & $p$ value \\
$D_{t-1}^{\text {ln }}$ & 1.521 & 0.000 \\
$D_{t-2}^{\ln }$ & -0.525 & 0.003 \\
$O_{t-1}$ & 0.014 & 0.271 \\
$O_{t-2}$ & -0.008 & 0.589 \\
Const & 0.018 & 0.819 \\
$O_{t}=$ & Coefficient & $p$ value \\
$D_{t-1}^{\ln }$ & -1.273 & 0.546 \\
$D_{t-2}^{\ln }$ & 1.044 & 0.621 \\
$O_{t-1}$ & 0.972 & 0.000 \\
$O_{t-2}$ & -0.153 & 0.441 \\
Const & 2.245 & 0.036 \\
\hline
\end{tabular}


Table 8 Coefficients' estimations of a VAR (2) model between the $D_{t}^{\ln }$ and $O_{t}$ for all phases. Top: model for $D_{t}^{\ln }$. Bottom: model for $O_{t}$. Italics: significant results with $5 \%$ level

\begin{tabular}{lll}
\hline$D_{t}^{\ln =}$ & Coefficient & $p$ value \\
$D_{t-1}^{\ln }$ & 1.343 & 0.000 \\
$D_{t-2}^{l n}$ & -0.347 & 0.000 \\
$O_{t-1}$ & 0.012 & 0.165 \\
$O_{t-2}$ & -0.001 & 0.942 \\
Const & -0.001 & 0.975 \\
$O_{t}=$ & Coefficient & $p$ value \\
$D_{t-1}^{\ln }$ & -0.658 & 0.503 \\
$D_{t-2}^{\ln }$ & 0.582 & 0.552 \\
$O_{t-1}$ & 1.098 & 0.000 \\
$O_{t-2}$ & -0.204 & 0.038 \\
Const & 0.904 & 0.027 \\
\hline
\end{tabular}

phases (Additional file 1: Table SH.1, left) and the correlation between $\left(D_{t}^{p}, O_{t+5}\right)$ during boom phases is not significant anymore (Additional file 1: Table SH.1, right). These results do not impact on conclusions. For the study of ARIMA models, three coefficient significances are modified: $\operatorname{cor}\left(\Delta D_{t}^{\text {res }}, \Delta G_{t}^{\mathrm{ln}}\right)$ during boom phases (Additional file 1: Table SH.2, left), cor $\left(\Delta D_{t}^{\mathrm{res}}, \Delta G_{t+5}^{\mathrm{ln}}\right)$ during all phases (Additional file 1 : Table SH.2, left), and $\operatorname{cor}\left(\Delta D_{t}^{\text {res }}, \Delta O_{t+3}\right)$ during recession phases (Additional file 1: Table SH.2, right). The significant negative correlation coefficient between $\left(\Delta D_{t}^{\mathrm{res}}, \Delta G_{t+5}^{\mathrm{ln}}\right)$ is the only result which is in favor of Hypothesis 1 , but it is not very significant ( $p$ value $=$ 0.049 ), and by itself, it is hardly a strong argument. Finally, for the study of VAR models, the biggest changes are the significant coefficients of $D_{t-1}^{\ln }$ and $D_{t-2}^{\ln }$ for explaining $G_{t}^{\mathrm{ln}}$ during boom phases (Additional file 1: Table SH.3, middle-left), and in the insignificant Granger causality from $O_{t} \rightarrow D_{t}^{\ln }$ during all phases (Additional file 1: Table SH.4 legend, middle-right). This does not lead to any change in our conclusions, as the Granger causality $D_{t}^{\ln } \rightarrow G_{t}^{\mathrm{ln}}$ is still a positive relationship, and the link $O_{t} \rightarrow D_{t}^{\ln }$ was already weak.

To sum up, the results obtained by omitting interpolated years hardly change the results found with complete time series.

\section{Conclusions}

As a conclusion, let us come back to the two tested hypotheses.

Hypothesis 1 Public debt has a negative impact on economic growth.

In view of the results of the performed tests, nothing allows us to support this hypothesis. Debt-toGDP ratio is not correlated with future GDP growth rates, debt residuals are positively correlated with future GDP differences, and Granger causality from debt to GDP is only significant for boom phases, but with a weak positive effect. Nevertheless, the analyses in the "Residuals of ARIMA models" and "Vector autoregression models and Granger causality" sections, which are probably the most relevant, show a negative link between GDP and future debt. Thus, the Swiss case seems to show, as suggested by a few other studies, yet without convincing results (Panizza and Presbitero 2013, pp. 7-9), that in the relationship between public debt and economic growth, it is the GDP increase that tends to decrease the debt, and not the opposite. However, it is noted that during the studied period, the debt-toGDP ratio in Switzerland has a mean of $49.2 \%$, which is far from the regime-switching threshold of 90\% suggested by Reinhart and Rogoff (2010), reached only during the years 1944 and 1945 . Hence, these conclusions concern only "low" debtto-GDP ratio, and the conventional theory seems incorrect in these conditions.
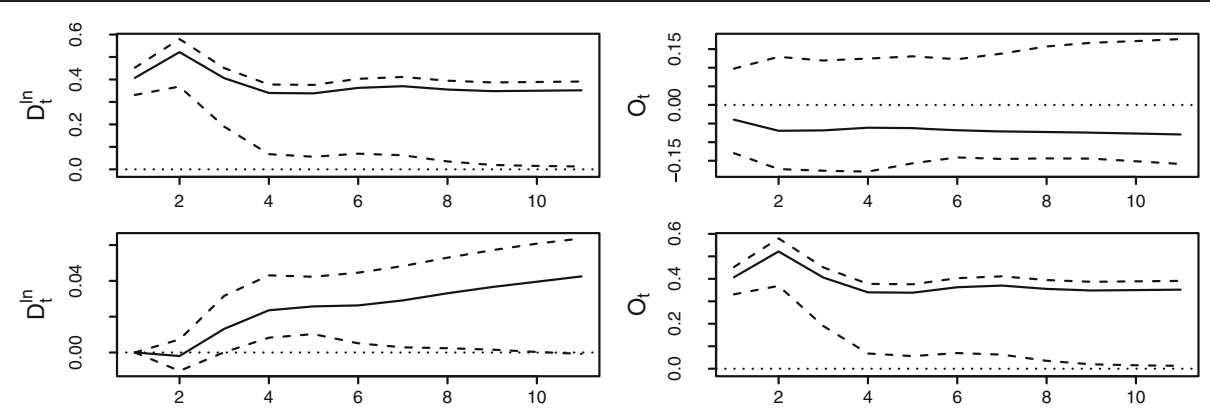

Fig. 4 Orthogonal impulse response functions with 95\% bootstrap $\mathrm{Cl}$ for boom phases. Top: from $D_{t}^{\ln }$ on $D_{t}^{\ln }$ and $O_{t}$. Bottom: from $O_{t}$ on $D_{t}^{\ln }$ and $O_{t}$ 

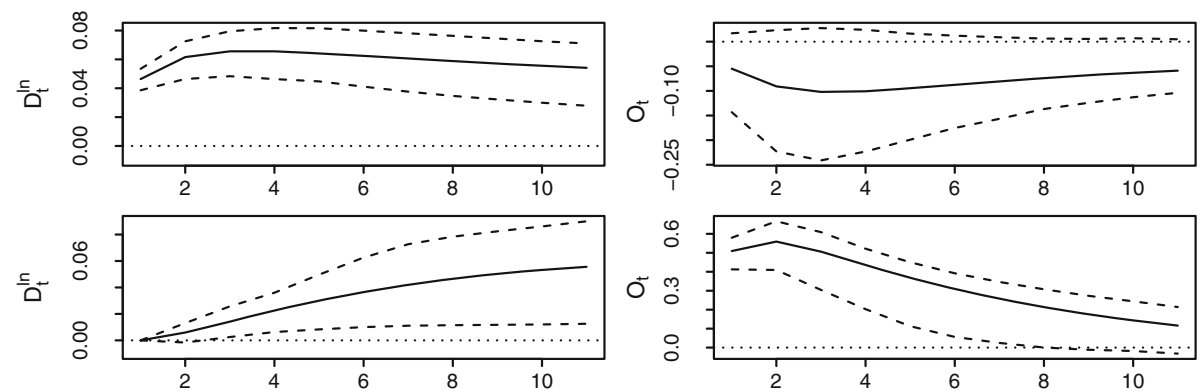

Fig. 6 Orthogonal impulse response functions with $95 \%$ bootstrap $\mathrm{Cl}$ for all phases. Top: from $D_{t}^{\ln }$ on $D_{t}^{\ln }$ and $O_{t}$. Bottom: from $O_{t}$ on $D_{t}^{\ln }$ and $O_{t}$

Hypothesis 2 Public debt raises long-term interest rates.

Similarly, this hypothesis is not supported by any result, although the results are less convincing. The tests performed in the "Residuals of ARIMA models" and "Vector autoregression models and Granger causality" sections show that long-term interest rates affect public debt, but not the other way around. However, the weak levels of significance in the results lead us to believe that relations between public debt and long-term interest rates are either negligible or subject to factors beyond the scope of this paper. Nevertheless, Hypothesis 2 does not hold empirically or seems, at best, overly simplistic in the Swiss case.

To sum up, our results corroborate conclusions found by the only other two empirical studies using the general gross public debt in Switzerland, namely the one by Schwab (1996) and the one (unpublished) by Gay (2012): the empirical analysis of the Swiss case, addressed over a long period of time (18942014), does not confirm the conventional theory about relations between public debt, economic growth, and interest rates.

\section{Endnotes}

${ }^{1}$ For a summary and an appraisal of the results of the main empirical researches, see for instance Schwab (1996, pp. 170-173), Panizza and Presbitero (2013) or Greiner and Fincke (2015, pp. 233-235).

${ }^{2}$ For instance, see Abbas et al. (2010) and Pescatori et al. (2014).

${ }^{3}$ Computed from Historical Statistics of Switzerland online, Table U.45, http://www.fsw.uzh.ch/histstat/main.php (accessed August 19, 2016); see also Guex (2012).

${ }^{4}$ This time series improves and extends the one found in Historical Statistics of Switzerland online, Table U.45.

${ }^{5}$ There is another study, but it is unpublished and a little rudimentary from the point of view of the statistical tools: Gay (2012).

${ }^{6} \mathrm{We}$ would like to deeply thank Dr. Alessandro Dozio, deputy at the city development and communication department, Lausanne, for his precious help in the gathering of data about the Confederation debt.

${ }^{7}$ Swiss National Bank, Historical Time Series. Interest Rates and Yields, Bern, Swiss National Bank, p. 11, and Schwab (1996, p. 123)
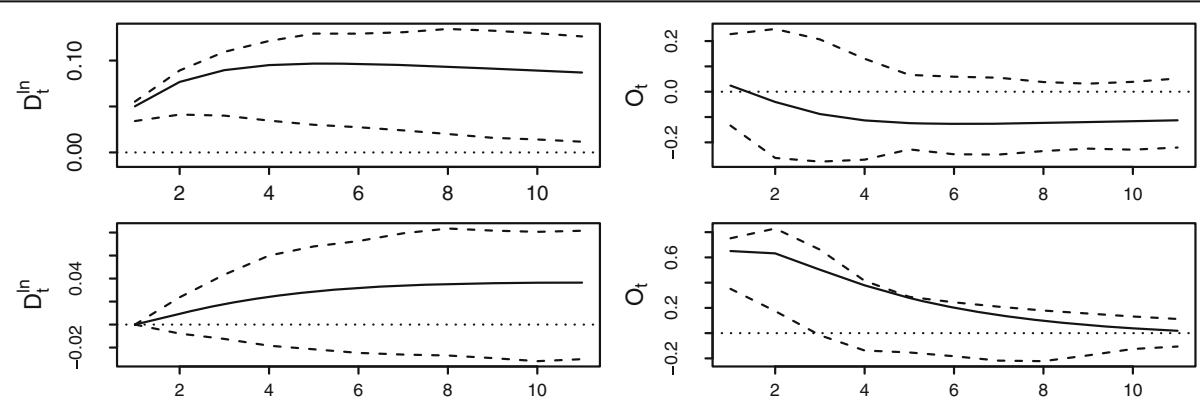

Fig. 5 Orthogonal impulse response functions with $95 \%$ bootstrap $\mathrm{Cl}$ for recession phases. Top: from $D_{t}^{\ln }$ on $D_{t}^{\ln }$ and $O_{t}$. Bottom: from $O_{t}$ on $D_{t}^{\ln }$ and $O_{t}$ 


\section{Additional file}

Additional file 1: A. Raw data. B. Deflated time series. C. GDP-weighted series. D. Ln-series. E. AFC and PAFC of series and first differences series. F. First differences series models and residuals. G. VAR models. H. Results without interpolated years (1910-2014). (ZIP 2685 kb)

\section{Authors' contributions}

Both authors read and approved the final manuscript.

\section{Competing interests}

The authors declare that they have no competing interests.

\section{Publisher's Note}

Springer Nature remains neutral with regard to jurisdictional claims in published maps and institutional affiliations.

\section{Author details}

'Louvain School of Management Research Institute, Université catholique de Louvain, B-1348 Louvain-la-Neuve, Belgium. ${ }^{2}$ History Section, Faculty of Arts, University of Lausanne, 1015 Lausanne, Switzerland.

Received: 5 June 2017 Accepted: 10 December 2017

Published online: 24 July 2018

\section{References}

Abbas, SA, Belhocine, N, El Ganainy, A, Horton, M (2010). A historical public debt database. In IMF Working Paper, WP/10/245.

Blanchard, OJ (2008). Crowding out. In SN Durlauf, LE Blume (Eds.), The new Palgrave dictionary of economics, second edition, (pp. 327-329). Basingstoke: Palgrave Macmillan

Box, GE, Jenkins, GM, Reinsel, GC, Ljung, GM (2015). Time series analysis: forecasting and control. Hoboken: John Wiley \& Sons.

Brunner, K. (1986). Deficits, interest rates, and monetary policy. Cato Journal, 5(3), 709-731.

Cooley, TF, \& LeRoy, SF. (1985). Atheoretical macroeconometrics: a critique. Journal of Monetary Economics, 16, 283-308

Dickey, DA, \& Fuller, WA. (1979). Distribution of the estimators for autoregressive time series with a unit root. Journal of the American Statistical Association, 74(366a), 427-431.

Elmendorf, DW, \& Mankiw, NG (1999). Government Debt. In JB Taylor, M Woodford (Eds.), Handbook of macroeconomics, Vol. 1C, (pp. 1615-1669). Amsterdam: Elsevier

Federal Administration of Finance (1978). Finances publiques en Suisse 1976. Bern. Federal Administration of Finance.

Federal Council. Compte d'Etat de la Confédération suisse 1943-1989. Bern.

Federal Statistical Office (1917). Annuaire statistique de la Suisse 1917. Bern: Stämpfi.

Federal Statistical Office (1932). Annuaire statistique de la Suisse 1932. Bern: Stämpfi.

Federal Statistical Office (1934). Annuaire statistique de la Suisse 1934. Bern: Stämpfi.

Federal Statistical Office (1939). Annuaire statistique de la Suisse 1939. Bern: Stämpfi.

Federal Statistical Office (1947). Annuaire statistique de la Suisse 1947. Bern: Stämpfi.

Federal Tax Administration (1965). Finances et impôts de la Confédération, des cantons et des communes 1963/64. Bern. Federal Administration of Finance.

Federal Tax Administration (1967). Finances et impôts de la Confédération, des cantons et des communes 1965/66. Bern. Federal Administration of Finance.

Federal Tax Administration (1973). Finances des cantons 1930-1971. Bern. Federa Administration of Finance.

Gay, B (2012). Les principes de la doxa libérale à l'épreuve de séries statistiques longues: la dette publique suisse (1894-2000). Lausanne: University of Lausanne, Master Thesis.

Granger, CWJ. (1969). Investigating causal relations by econometric models and cross-spectral methods. Econometrica: Journal of the Econometric Society, 37(3), 424-438
Granger, CWJ, \& Newbold, P. (1974). Spurious regressions in econometrics. Journal of Econometrics, 2, 111-120.

Greiner, A, \& Fincke, B (2015). Public debt, sustainability and economic growth. Theory and empirics. Cham: Springer International Publishing.

Guex, S (1993). La politique monétaire et financière de la Confédération suisse 1900-1920. Lausanne: Payot.

Guex, S (2012). Öffentliche Finanzen und Finanzpolitik. In P Halbeisen, M Müller, B Veyrassat (Eds.), Wirtschaftsgeschichte der Schweiz im 20. Jahrhundert, (pp. 1077-1129). Bern: Schwabe.

Johansen, S. (1988). Statistical analysis of co-integration vectors. Journal of Economic Dynamics and Control, 12(2), 231-254

Kirchgässner, G (2004). Die langfristige Entwicklung der Bundesfinanzen, 1960-2002. St. Gallen: Universität St. Gallen.

Kwiatkowski, D, Phillips, PC, Schmidt, P, Shin, Y. (1992). Testing the null hypothesis of stationarity against the alternative of a unit root: how sure are we that economic time series have a unit root? Journal of Econometrics, 54, 159-178.

Müller, M, \& Woitek, U (2012). Wohlstand, Wachstum und Konjunktur. In P Halbeisen, M Müller, B Veyrassat (Eds.), Wirtschaftsgeschichte der Schweiz im 20. Jahrhundert, (pp. 91-222). Bern: Schwabe.

Panizza, U, \& Presbitero, AF. (2013). Public debt and economic growth in advanced economies: a survey. Swiss Journal of Economics and Statistics, 149(2), 175-204.

Park, JY, \& Phillips, PCB. (1989). Statistical inference in regressions with integrated processes: part 2. Econometric Theory, 5, 95-132.

Pescatori, A, Sandrim, D, Simon, J (2014). Debt and growth: is there a magic threshold? In IMF Working Paper, WP/14/34.

Reinhart, CM, \& Rogoff, KS. (2010). Growth in a time of debt. American Economic Review, 100(2), 573-578.

Schwab, B (1996). Ökonomische Aspekte der Staatsdefizite und Staatsverschuldung in der Schweiz. Bern: Haupt.

Sims, CA, Stock, JH, Watson, MW. (1990). Inference in linear time series models with some unit roots. Econometrica, 58, 113-144.

Steiger, J (1915). Der Finanzhaushalt der Schweiz. Die Kantone (Vol. III). Bern: Stämpfi.

Steiger, J (1916). Der Finanzhaushalt der Schweiz. Die Gemeinden (Vol. IV). Bern: Stämpfi.

Steiger, J, \& Higy, C (1934). Finanzhaushalt der Schweiz, Bund, Kantone, Gemeinden. Bern, Wyss.

Swiss National Bank (1944). Manuel statistique du marché financier suisse. Bern: Schulthess.

Toda, HY, \& Yamamoto, T. (1995). Statistical inference in vector autoregressions with possibly integrated processes. Journal of Econometrics, 66(1), 225-250.

Yule, UG. (1926). Why do we sometimes get nonsense-correlation between timeseries? - a study in sampling and the nature of time-series. Journal of the Royal Statistical Society, 89(1), 1-63.

\section{Submit your manuscript to a SpringerOpen ${ }^{\circ}$ journal and benefit from:}

- Convenient online submission

- Rigorous peer review

- Open access: articles freely available online

- High visibility within the field

- Retaining the copyright to your article

Submit your next manuscript at $>$ springeropen.com 